\title{
Shifting towards online training-Possible challenges from Educators/Trainers perspective in Indian setting
}

Snehil Singh ${ }^{1}$, Sanjay Gupta ${ }^{2}$, Lokesh Sharma ${ }^{3}$, Mainak Chatterjee ${ }^{4}$, Sumeet Juneja ${ }^{5}$, Paritosh Panigrahi ${ }^{6}$, Hitesh Kumar ${ }^{7}$, Harshad Thakur ${ }^{8}$

${ }^{1}$ Coordinator \& Team Lead - NCCVMRC, National Institute of Health and Family Welfare, New Delhi; ${ }^{2}$ Professor \& Head, Department of MCHA, National Institute of Health and Family Welfare, New Delhi; ${ }^{3}$ EVM \& MIS Coordinator, NCCVMRC, National Institute of Health and Family Welfare, New Delhi; ${ }^{4}$ Immunization Specialist, UNICEF Country Office, India; ${ }^{5}$ Immunization Training Coordinator, NCCVMRC, National Institute of Health and Family Welfare, New Delhi; ${ }^{6}$ Technical Officer iSC, NCCVMRC, National Institute of Health and Family Welfare, New Delhi; ${ }^{7}$ Training coordinator - Cold Chain, NCCVMRC, National Institute of Health and Family Welfare, New Delhi; ${ }^{8}$ Director, National Institute of Health and Family Welfare, New Delhi

\begin{tabular}{|c|c|c|c|c|c|c|c|}
\hline Abstract & Introduction & Methodology & Results & Conclusion & References & Citation & Tables / Figures \\
\hline \multicolumn{8}{|c|}{ Corresponding Author } \\
\hline \multicolumn{7}{|c|}{$\begin{array}{l}\text { Mr Lokesh Sharma; “318, Sector E, Pocket -2, Vasant Kunj, New Delhi - } 110070 \\
\text { E Mail ID: lokesh.L85@gmail.com }\end{array}$} & 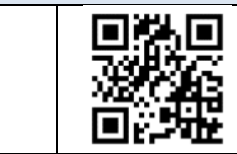 \\
\hline
\end{tabular}

\section{Citation}

Singh S, Gupta S, Sharma L, Chatterjee M, Juneja S, Panigrahi P, Kumar H, Thakur H. Shifting towards online training-Possible challenges from Educators/Trainers perspective in Indian setting. Indian J Comm Health. 2020;32(4):620-623. https://doi.org/10.47203/IJCH.2020.v32i04.002

Source of Funding: Nil Conflict of Interest: None declared

Article Cycle

\begin{tabular}{|r|}
\hline Received: 07/11/2020; Revision: 18/11/2020; Accepted: 09/12/2020; Published: 31/12/2020 \\
\hline This work is licensed under a Creative Commons Attribution 4.0 International License. \\
\hline
\end{tabular}

\section{Abstract}

Emergence of novel coronavirus has resulted in global chaos within days of its first detection in Wuhan, China. To curb the spread of Covid-19, stringent actions like lockdown and social distancing were imposed comprehensively around the World, training Institutes in India and globally, were widely affected by these restrictions. Henceforth, giving rise to an immediate need to extemporize modules to be adjusted to disseminate knowledge through elearning platforms. This observation is an experience document to share the challenges and usefulness of shifting towards e-learning encountered by The National Cold Chain and Vaccine Management Resource Centre (NCCVMRC), Delhi. This piece additionally discusses the practices that could assist academic institutions in dealing with limitations associated with moving toward e-learning.

\section{Keywords}

Virtual Training; Online Training; Educators; Trainers

\section{Introduction}

Worldwide metastasis of novel coronavirus COVID19 has caused immense alterations among every walk of human existence and social interaction(1). Education and training sector being as vulnerable to these adjustments as any other domain(2). Owing to its extremely infectious nature, the COVID-19 pandemic enforced the closure of training institutes globally. All the traditional classroom training were restricted as an instant consequence, to achieve the norms of social distancing which can perhaps aid in obliterating the infection curve and lessen the resultant fatalities(3).

Educational institutions in India predominantly bank on traditional methods of training, utilizing conventional setup of in-person training and lectures in a teaching space. While over the years, there is a marked shift towards blended learning, still most of 
the academic institutes are guided by the existing orthodox learning methodologies. An unexpected outbreak of the Covid-19 pandemic caused by Corona Virus (SARS-CoV-2) shuddered the entire world (4). This complete shutdown kind of circumstances has tested the education system globally and coerced the educators to shift to digital platforms and online modules almost instantaneously. Academic institutions were required to shift from their traditional pedagogical approach to online teaching-learning. The article recognises the possible barriers to swiftly shift from traditional methods of learning towards e-learning among adult professionals through analysing the limitations faced by the authors while converting and conducting traditional trainings into e-trainings at The National Cold Chain and Vaccine Management Resource Centre (NCCVMRC-NIHFW), New Delhi. This article also put some light on methodologies that could assist academic institutions in dealing with challenges associated with shifting towards elearning.

Challenges Associated with Online Teaching and elearning for educators and academic institutes

Academic institutes are subjected to multi-faceted challenges while shifting towards e-learning. (5)This includes identifying and procuring suitable online training platforms, training the resource persons on acquired technologies, and also restructuring the existing courses and modules.

E-learning has some inherited limitations like - it necessitates access to digital technology like a computer or a mobile device; steady and dependable internet connectivity especially in remote areas.; Additionally, practice-based learning is difficult to impart using e-platforms, and determining the proficiencies which can be deliberated and evaluated through e-learning modules is another challenge of web-based learning. Users can face many technical difficulties that hinder and slowdown the teaching-learning process(6). Contending demands on participants' and educators' time is also identified as a limitation of e-learning programs.

We have identified the following points of deliberation as possible challenges toward shifting to e-learning from educators' point of view

A. Erudition methodologies and social contests Sywelem et al., 2012(7) cited the importance of trainings being imparted in a manner more compatible with the known learning style to the knowledge seeker. The most recommended method of teaching is to develop modules compatible with the learning styles of the trainees. In traditional classrooms through personal interaction, educators can modify instructions as per learner's demand, which remains a major hurdle in an e-learning program. Different beneficiaries have different demands in a virtual environment - some prefer videos over traditional presentations, some are more used to taking notes, some prefer interactive sessions, leaving educators and academics to face difficulties in understanding and modify their teachings best suited to the target audience. Academicians and Institutes are required to invest time, effort, and finances to device training materials best suited to the needs of the targeted cohort. If educators are not able to modify their expertise accordingly then there is a possibility of underachievement of the desired outcome despite infrastructure support.

\section{B. Scholastic Barriers of e-learning}

After the preparation of the desired training modules best suited to the target audience and in harmony with the available e- platforms, the way of delivery of the trainings is another challenge faced by educators while shifting towards e-learning.

Parallel to learner's behaviour, educators too are used to a definitive style of delivering information. Making pedagogical alterations to deliver the intended training is of equal importance. It is crucial to facilitate the trainees in accessing the available eknowledge beyond just making it accessible to them.

\section{Infrastructure Restrictions}

Nielsen et al., 2011(8), brought focus to the fact that there are pre-existing internal Information Technology systems with the academic institutes. These systems have robust data and mechanisms, syncing these with the changing e- environment and possibly newly procured e-learning system is a demanding task for the concerned professionals.

Technical glitches, software viruses, and speed are critical if academics are to use the system and is critical to the success of e-learning technology. Any lapses in the proper functioning of the installed system could contribute to creating a negative behaviour towards e-learning, which has sizeable complications for institutions as they have devoted huge finances for the same.

\section{Technical training needs of educators for delivering online trainings}

Technical barriers are the individual limitations of instructors/ facilitators to effectively use the 
available e-platform to educate the learners. There is a need to provide technical trainings to educators which in turn will enable them to adapt to the elearning features and functions correctly. While reviewing the literature on e-learning, multiple papers citing evidences of sub-standard training provided by institutions to academics were available. Varied issues ranging from inadequate training, lesser than the required training, the lapse in handson practices, etc pose a greater challenge for educators in shifting towards e-learning.

\section{E. Time Management Challenges}

Conrad, 2004(9)stated e-learning to be more time consuming for academicians than the prevailing traditional classroom methods. Studies indicate that apart from working hours e-learning increases the academician's effort manifolds, i.e. up to $14 \%$ to teaching effectively.(10) The literature points out that while the traditional methods of learning have changed, teacher and student roles remain, and elearning allows 24 hours a day for a class to run, and verbal conversation has been replaced with a permanent written discussion forum where students can update any time of the day or night. This has put educators and institutes under tremendous pressure of time management.

\section{Recommendations to mitigate the challenges}

Through various literature reviews and our own experience, it cannot be denied that e-learning, despite being a boon for educational institutes and learners, comes with inherent challenges not only for the target beneficiaries but also for the educators/ trainers. To achieve the parallel impact from elearning, as from the traditional models, it is crucial to build the capacity of trainers involved in imparting e-education.

We suggest the followings pointers be taken into consideration while shifting towards e-learning

1. Comprehensive training of the academicians/ trainers on understanding and using e-platforms, to equip them with the required technical knowledge regarding the efficient use of $e$ platforms.

2. Training of educators on methods of effectual communication in an e-classroom/ learning session can enable educators, to communicate and understand the learners' needs in a virtual environment better. This would aid in the modification of modules more suited to learner's requirements.

3. Institutes can invest in technologies that are user-friendly and allows didactic communication between the trainer and the trainee.

4. Online KAP assessments, pre- and post-tests, and the use of available feedback apps should be encouraged to create a physical classroom-like environment and to engage educators and learners more in a virtual session.

5. Well placed feedback mechanism comprising questions on the suitability of content and delivery methodologies to e-learning, should be taken and analysed for aiding Educators to prepare modules and deliver the same effectively.

6. Experts can prepare manuals for Educators on the development of e-modules as well as on the use of e-learning platforms.

The sudden shift in training methodologies, due to the emergence and spread of the COVID-19 pandemic has stressed the education systems globally in every possible manner. However, elearning has opened the doors of possibilities in academics. Reach of expert educators to the remotest areas seems a more possible outcome now, the only need is to prepare and arm the trainers with the desired technical knowledge to ensure effective outcomes through e-learning.

\section{Summary}

With the global spread of covid-19, educational institutes were left with no choice than to shift towards e-learning. Apart from the hindrances present at the learners end in obtaining education through e-platforms, authors being involved in multiple capacity building programs across India, encountered and identified multiple limitations faced by the educators and institutes while imparting e-learning. Through this piece, the authors have tried to discuss the same to address and help the other institutes across the globe with parallel infrastructure to identify and modify these shortcomings at an early stage.

\section{Authors Contribution}

All authors have contributed equally.

\section{References}

1. Alradhawi M, Shubber N, Sheppard J, Ali Y. Effects of the COVID-19 pandemic on mental well-being amongst individuals in society- A letter to the editor on "The socioeconomic implications of the coronavirus and COVID-19 
2. Digital Learning During the COVID-19 Pandemic [Internet]. [cited 2020 Nov 5]. Available from: https://www.ncbi.nlm.nih.gov/pmc/articles/PMC7273026/

3. Aminizadeh $\mathrm{M}$, Rasouli Ghahfarokhi SM, Pourvakhshoori N, Beyramijam M, Majidi N, Shahabi Rabori MA. Comparing the effects of two different educational methods on clinical skills of emergency intermediate technician: A quasiexperimental research. J Educ Health Promot. 2019 Mar 14;8:54. doi: 10.4103/jehp.jehp_323_18. PMID: 31008121; PMCID: PMC6442246.[PubMed]

4. Zheng J. SARS-CoV-2: an Emerging Coronavirus that Causes a Global Threat. Int J Biol Sci. 2020 Mar 15;16(10):16781685. doi: 10.7150/ijbs.45053. PMID: 32226285; PMCID: PMC7098030.[PubMed].

5. The Impact of Training and Other Variables on the Preparation of the Public Welfare Workforce:

[Shifting towards online...] | Singh S et al Administration in Social Work: Vol 33, No 3 [Internet]. [cited 2020 Nov 5]. Available from: https://www.tandfonline.com/doi/abs/10.1080/03643100 902987903

6. Favale T, Soro F, Trevisan M, Drago I, Mellia M. Campus traffic and e-Learning during COVID-19 pandemic. Comput Netw. 2020 Jul 20;176:107290.

7. Sywelem MMG, Al-Harbi Q, Fathema N, Witte J. Learning Style Preferences of Student Teachers: A Cross-Cultural Perspective. Inst Learn Styles J. 2012;1:10-24.

8. Nielsen R $\varnothing$, Hennen L, Korthagen I, Aichholzer G, Lindner R. Options for Improving e-Participation at the EU Level. 2020.329-59.

9. Conrad D. University instructors' reflections on their first online teaching experiences. JALN Vol. 2004;8(2):31-44.

10. Tomei L. The Impact of Online Teaching on Faculty Load: Computing the Ideal Class Size for Online Courses. J Technol Teach Educ. 2006 Jul;14(3):531-41. 